Georgia State University

ScholarWorks @ Georgia State University

\title{
3-2-2014
}

\section{Migrant Scientists and International Networks}

\author{
Giuseppe Scellato \\ Polytechnic of Turin, giuseppe.scellato@polito.it \\ Chiara Franzoni \\ Politecnico di Milano \\ Paula Stephan \\ Georgia State University, pstephan@gsu.edu
}

Follow this and additional works at: https://scholarworks.gsu.edu/uwrg_workingpapers

\section{Recommended Citation}

Scellato, Giuseppe; Franzoni, Chiara; and Stephan, Paula, "Migrant Scientists and International Networks" (2014). UWRG Working Papers. 84.

https://scholarworks.gsu.edu/uwrg_workingpapers/84

This Article is brought to you for free and open access by the Usery Workplace Research Group at ScholarWorks @ Georgia State University. It has been accepted for inclusion in UWRG Working Papers by an authorized administrator of ScholarWorks @ Georgia State University. For more information, please contact scholarworks@gsu.edu. 


\section{W. J. Usery Workplace Research Group Paper Series}

Working Paper 2014-3-2

March 2014

\section{Migrant Scientists and International Networks}

Giuseppe Scellato

Politecnico di Torino

Chiara Franzoni

Politecnico di Milano

Paula Stephan

Georgia State University

AndREW Young SchoOl 


\title{
Migrant Scientists and International Networks
}

\author{
Giuseppe Scellato \\ Department of Management and Production Engineering, Politecnico di Torino, 10129 Turin, Italy \\ Bureau of Research on Innovation, Complexity and Knowledge, Collegio Carlo Alberto, 10024 Moncalieri, Italy. \\ giuseppe.scellato@polito.it
}

\section{Chiara Franzoni}

School of Management, Politecnico di Milano, 20133 Milan, Italy.

\section{Paula Stephan}

\author{
Andrew Young School of Policy Studies, Georgia State University, Atlanta, GA 30302, USA \\ National Bureau of Economic Research, Cambridge, MA 02138, USA \\ Department of Economics Cognetti De Martiis, Università di Torino, Italy
}

\begin{abstract}
We examine collaboration patterns of foreign scientists working in one of 16 countries in 2011 and compare them to the collaboration patterns of nonmigrant scientists and scientists with some international experience who have returned. Data come from the GlobSci survey. Major findings are that both foreign-born scientists and returnees have larger international research networks than do native researchers who lack an international background. The higher incidence of international collaboration among migrants is driven primarily by those who did not get their $\mathrm{PhD}$ training in the destination country but rather came for a postdoctoral position or directly for employment. We also find that a sizeable share of foreign born collaborate with researchers located in their country of origin and that migrants are also likely to collaborate with individuals from their home country who are working or studying in a third country (diaspora effect). Finally, the relative strength of the origin country's science base matters in the sense that those who come from a relatively stronger base have superior networks compared to those coming from a relatively weaker science base.
\end{abstract}




\section{INTRODUCTION}

There is considerable interest in policies that promote the international mobility of students and researchers. The Erasmus program in Europe, for example, promotes the mobility of individuals for study; the Marie Curie program promotes the mobility of postdoctoral scholars and established scientists both within and outside of Europe. In recent years several countries have adopted policies to retain mobile scientists. Both Canada and Australia, for example, provide a fast track to permanent residency for migrant scientists trained in country and the United States is currently considering a policy that would grant green cards (permanent residency) to temporary residents at the time that they receive their $\mathrm{PhD}$ in a STEM field (science, technology, engineering and mathematics) in the US. Policies also exist to attract emigrant scientists back to the country of origin and to promote the exchange and communication of nationals abroad with the home land. The Ramon y Cayal program, for example, was designed to attract postdoctoral researchers back to Spain; China and India offer high salaries to returnees as well as visiting positions. New Zealand has promoted policies to facilitate communication and cooperation between New Zealanders abroad (particularly in Australia) and scientists who are working in country (Davenport, 2004).

The implicit assumption underlying these various initiatives is that mobility fosters productivity and enhances networks. Empirical work concerning the importance and size of such effects, however, relies almost exclusively on case studies focusing on specific countries (Nagaoka, et al. 2013; Baruffaldi and Landoni, 2013) or on specific policy initiatives, such as the Fulbright program in the United States (Kahn and MacGarvie, 2010). To date, no research has addressed the generalizability of these findings across countries and across characteristics of migrants such as career stage at the time of migration. Nor has the growing complexity of high skilled mobility, characterized by circular moves, partial migrations, student and temporary mobility (Ackers and Gill, 2008) been adequately studied. Moreover, the country specific focus of previous studies does not allow for an assessment of the impact of the diaspora on the international collaboration capability of migrants.

This paper contributes to our understanding by examining network patterns of migrant scientists working in sixteen countries and comparing these patterns to those of nonmigrant scientists. ${ }^{1}$ The sixteen core countries include ten in Europe (Belgium, Denmark, France, Germany, Italy, the Netherlands, Spain, Sweden, Switzerland and the UK), as well as Australia, Brazil, Canada, India, Japan and the US. Our focus is active researchers in the fields of biology, chemistry, earth and environmental sciences, and materials. Data come from the GlobSci survey, conducted in the spring of 2011 by the three authors (Franzoni et al., 2012). The methodology involved surveying corresponding authors of articles published in 2009 in the four fields who were studying or working in one of the 16 countries. Collectively the core countries produce about 70 percent of all articles published in these fields. The overall response rate was about 40 percent (Franzoni et al., 2012). The survey resulted in 19,183 responses. The data collected through the survey allow us to control for a number of individual characteristics that cannot be observed through alternative research approaches such as bibliometric indicators or the analysis of the CVs of researchers. Moreover, our survey methodology permits us to use nonbibliometric measures to assess the size and geographic location of the international network.

Major findings are that both foreign-born scientists and returnees have larger international research networks than do native researchers in core countries who lack an international background. Such patterns hold across the sixteen countries as well as when we conduct the

\footnotetext{
${ }^{1}$ Here we address issues related to the relationship of migration to international collaboration. In a related paper (Franzoni et al. 2014) we address the relationship of international mobility to performance.
} 
analysis separately for the US, European countries and other countries. Second, the higher incidence of international collaboration among migrants is driven primarily by those who did not get their $\mathrm{PhD}$ in the destination country but rather came for a postdoctoral position or directly for employment at a university or public research centre in the destination country after doctoral training. Such results suggest that research links established during doctoral training by migrant researchers matter and are portable. It is consistent with the third finding that a sizeable share of foreign-born scientists (slightly more than $40 \%$ ) report research collaborations with researchers located in their country of origin. Moreover, and consistent with the portability concept, is the fourth finding that diaspora networks (Meyer, 2001) matter to the extent that migrants collaborate with individuals from their home country who are studying or working in a third country. A fifth finding is that the size of a migrant's network correlates with the relative strength of the origin country's science base: those coming from countries with relatively stronger science bases have superior networks compared to those coming from relatively weaker countries.

The paper is organized as follows. In section 2 we define what we mean by migration and discuss migration and research network formation and formulate the framework for our empirical work. In section 3 we introduce the characteristics of the GlobSci survey, the related datasets and discuss the evidence on international mobility patterns for the 16 core countries. In section 4 we present the econometric modelling of the data and show results. Section 5 summarises the main findings and discusses implications for policy.

\section{SCIENTISTS MIGRATION AND INTERNATIONAL RESEARCH NETWORKS}

Despite increases in connectivity and bandwidth, mobility continues to play a key role in the production of scientific knowledge. A key factor is the importance of tacit knowledge to the production of knowledge, and thus the need for face to face interaction (Stephan, 2010). Mobile scientists, who have been working face to face with scholars in multiple locations, are naturally one primary vehicle of diffusion, enabling knowledge to move with them and to be used and shared across different locations. Diffusion of tacit knowledge occurs in part because movers bring knowledge to the destination and in part because mobile scientists establish collaborations with and across the local communities they bridge (Gibson and McKenzie, 2012). Although the role of mobility in network formation has been acknowledged for a considerable time, until recently, due largely to the lack of data, there have been few attempts to link mobility to research networks and to map the extent to which mobility networks and research networks overlap.

We try to fill this gap in this paper. We do so by focusing on one specific kind of mobility, namely international migration. We study the international collaborations of migrant scientists, including those who returned to the origin country. We do not study within-country moves and we do not study short-term international mobility (e.g. research visiting periods) ${ }^{2}$.

A fact known with considerable certainty is that research is increasingly a collaborative effort. Research teams are becoming larger and a growing proportion of teams are established between scientists based at different institutions and in different countries (Wuchty, et al., 2007; Jones et al., 2008, Gazni et al., 2012). It has been estimated that in the first decade of this century, international collaborations grew from 14\% of all publications in ISI in 2000 to $18 \%$ in 2009 . The increase occurred in all scientific fields, with the exception of physics $(-0.5 \%)$ and occurred largely among teams of 3 or more co-authors (Gazni et al., 2012). There is further evidence that

\footnotetext{
2 For within-country mobility see Fernandez-Zubieta et al. (2013). For short term mobility see Kahn and MacGarvie (2010) and Jöns (2009).
} 
this increase is not just recent, but started at least during the 1980s. For example in the US, the foreign-share of internationally collaborated papers increased steadily from about $5.1 \%$ per year during the 1980 s to about $7.4 \%$ during the 1990 s, with the increase being driven primarily by collaborations with Asian and European institutions (Adams et al., 2005). The share of European papers co-authored with US-based researchers increased from 5.9\% in 1985 to $9.5 \%$ in 1995, while papers co-authored with Japan-based researchers increased from $0.5 \%$ to $1.3 \%$ and those with researchers based in Canada from $0.9 \%$ to $1.6 \%$ (Georghiou, 1998).

We also know that the rate of the tertiary educated who become migrants has increased during the same decades at a high pace and that a large proportion of highly-educated migrants circulates among relatively wealthy countries (Docquier et al., 2009). The lack of data, however, makes it impossible to draw a link between the increasing migration of people and increasing long-distance networks in science. Nonetheless, it is somewhat puzzling that migration has been left in the background, if mentioned at all, in the literature that has discussed reasons behind increased international collaborations (Katz and Martin, 1997; Georghiou, 1998; Gazni, et al., 2012). Instead, prior studies have documented that the increase in collaboration has been enabled by the advent of email and inexpensive international communication (Ding et al., 2010), by mechanisms of preferential attachment that researchers develop to gain reputation and visibility (Wagner and Leydesdorff, 2005), by the increase of bilateral research agreements, especially with regard to big science projects (Georghiou, 1998), and in consequence of the widespread use of funding schemas that mandate cross-country collaboration in the European area (Defazio et al., 2009).

Without denying the relevance of these factors, a first aim of this paper is to investigate the understudied link between migration and network formation and to provide evidence regarding the extent to which mobility is a likely engine of international research collaboration. Due to the structure of our data, we cannot claim to observe a causal relation between international mobility and network participation. To the extent that migration happens because of international collaborations among teams, this relationship may indeed go the opposite way. Moreover, we do not have longitudinal data and thus cannot observe changing patterns over time. Nonetheless, we take a first step by examining the proportion of research conducted in international teams that involves investigators who had a prior experience of work or study in a different country and compare the extent to which domestic and foreign-born scientists differ in their propensity to be involved in international teams.

A second focus of this paper is to examine the kinds of social connections that are easily carried forward when a scientist migrates from one country to another. One strength of our study is that our measures of international collaboration do not rely on co-authorship patterns. Although the latter provide a reasonable proxy of scientific collaborations, and one largely used by scholars, there are several well-known limitations to this approach (Katz and Martin, 1997). One limitation is that co-authorships capture only the formal and most visible part of collaborations, overlooking informal collaborations, the so-called "invisible colleges" (de Solla Price, 1963; Crane, 1972), that may not result in joint authorship, but are nonetheless extremely relevant in explaining the progress of science. A second limitation is that publication databases, such as ISI, are known to be biased in favor of English-language journals and are therefore prone to undercount collaborations occurring among countries with a substantial corpus of publications in national language, such as China, Korea and Japan. A third and more important limitation is that co-authorship provides no information concerning how or when the connection among the authors was established and what role each author had in the collaboration. ${ }^{3}$ In our analysis we

\footnotetext{
${ }^{3}$ Biographical sketches, provided in rare cases by journals, are typically difficult to analyze and prone to assessment biases (see for example Furukawa et al., 2011).
} 
rely on survey data that enable us to capture information on collaborations beyond formal coauthorship, and use co-authorship only to validate and assess the robustness of our findings.

Our data also allow us to qualify the collaboration based on several characteristics of the scientist. One characteristic of interest in this paper is whether the scientist is foreign born and, if she is, the point in the career that she migrated to the country of destination. For the scope of our work, we wish to see if the alleged advantage of foreign born in establishing international collaborations varies depending on the intensity of the social connections with the scholarly community that existed at the time of entry into the foreign country. Prior research has documented the relevance and endurance of social relationships that people keep with individuals who were formerly colocated (Saxenian, 1994; Almeida and Kogut, 1999). Agrawal, Cockburn and McHale (2006) document this relationship at the individual level, by studying inventors who move from one company to another and show that movers disproportionally cite colleagues at their prior location. They explain the finding by suggesting that even if the inventors could no longer benefit from lower communication costs, frequent informal discussions and casual meetings that happen among co-workers in the same geographic location, social relationships forged when they worked together facilitate the transmission of knowledge across long distances, in the spirit of the spread of "intellectual innovations" that happens in invisible colleges (Crane, 1972).

Concerning the international mobility of scientists, we expect that the extent to which social relations are likely to endure and facilitate collaboration depends on the knowledge and expertise of the people involved. Therefore one condition that enhances knowledge transmission should be that the mover is acquainted with colleague-scholars at the time he or she migrates. Moreover, one would expect the effect to be stronger, the stronger the science base in the country of origin. To the extent that a senior scientist has more social capital with other scientists than a junior scholar and a junior scholar has more social capital with other scholars than an early trainee, we would expect to observe variation in the degree to which the timing of entry in terms of career stage into the destination country is associated with international network formation. A second contribution of this paper, therefore, is to investigate if the size of a migrant's international network depends upon the scientist's career stage at the time the scientist departed the home country. A related contribution is to examine the extent to which the international network of the migrant depends upon the relative strength of the science base of the sending country where the social capital with other scientists was formed. ${ }^{4}$

A third area of contribution of this paper is to investigate national ties. Prior research conducted on inventors has documented the existence of "ethnic communities" (Kerr, 2008; Agrawal et al., 2011), i.e. of working relationships among expats of the same country who live away from their home country and communicate either among each others or with the people who remained in the home country. In this paper we measure the extent to which the international collaborations that the foreign-born keep are likely to be explained by national links. We further distinguish between two types of national links: collaborations established with scholars based in the respondent's home country and collaborations established with same-nationals of the respondents who are expat in a third country, which we refer to here as diaspora networks.

To the best of the authors' knowledge, there are few prior studies that have assessed the degree to which migrant scientists maintain relationships with their home country and virtually no study that has assessed the relevance of diaspora networks in the international collaborations of scientists. With regard to the former, Nagaoka, Igami and Walsh (2013) use two surveys of scientists administered in Japan and in the US and find that in both countries the odds of the

\footnotetext{
${ }^{4}$ The hypothesis that a relationship exists between network size and strength of the science base of the home country is consistent with prior studies that indicate that a large share of international collaborations happen between countries with relatively stronger science bases (Gazni et al., 2012) and (Glanzel 2001).
} 
research having international collaborators (as opposed to involving solely domestic collaborators) was larger for those articles whose corresponding author has had at least one year of research experience abroad. They make no distinction, however, regarding country of prior mobility of the corresponding author. Landoni and Baruffaldi (2013) analyze 497 scientists based either in Italy or in Portugal and find that more than half keep some sort of formal or informal link with their country of origin. They further find that keeping informal links with the origin country was associated with higher productivity. Jöns (2007) investigate the relationship between knowledge production and spatial movement by examining mobility to Humboldt University in Germany. Other studies have looked at the networking activities of the returnees to the home country, finding in general a positive association (Jonkers and Tijssen, 2008; Jonkers and CruzCastro, 2013). Meyer and Wattiaux (2006) provide a discussion of extant evidence on the determinants and effects of the formation of diaspora-based international networks. Other recent studies have addressed the international knowledge flows from diaspora focusing on inventors (Agrawal et al. 2011) and entrepreneurs (Saxenian, A. 2002, 2005).

\section{DATASET AND SUMMARY STATISTICS}

\subsection{The GlobSci survey}

We surveyed active researchers based in 16 countries and working in the four scientific disciplines of biology, chemistry, earth and environmental sciences, and materials science during the period February-June 2011. Surveyed countries are: Australia, Belgium, Brazil, Canada, Denmark, France, Germany, India, Italy, Japan, Netherlands, Spain, Sweden, Switzerland, United Kingdom, United States.

In order to construct the sample, we selected all journals classified by the database ISI - Web of Science-- belonging to one of the four disciplinary fields and sorted them by Impact Factor for all subfields of the four disciplines. Impact Factor was taken from the latest available release of the Journal Citation Report of Thomson-Web of Science ${ }^{\circledR}$. We then randomly picked a selection of four journals in each quartile of the Impact Factor distribution in each of the subfields of the four disciplines. In the aggregate, this selection corresponds to approximately $30 \%$ of all journals published in the four fields. Starting from these lists of journals, we then downloaded full bibliographic data of all scientific articles published in the selected journals in 2009 and retrieved the email address of the corresponding authors of each of the survey articles. In case of multiple corresponding authors, we picked the first name on the list. In the case of corresponding authors appearing repeatedly in the list, we randomly selected one record ${ }^{5}$. In order to build country panels, we coded these records, based on the final digits of the domain of the email address (e.g. ".au" for Australia; ".be" for Belgium, etc.). We identified US authors by those having ".edu" in the address, thereby restricting the US sample to academic researchers.

We prepared 16 country panels. This procedure produced a sample of 47,304 unique email addresses of scientists divided in 16 country panels. Country panel sizes vary considerably, reflecting by construction the size of the country research-active population. The largest panel was the US, with 14059 observations; the smallest was Denmark with 513 (See Annex A Table A1). ${ }^{6}$ Country responses reflect both the size of the underlying research-active population of

\footnotetext{
${ }^{5}$ In the four selected fields $95 \%$ or more of all articles contain an email address for the corresponding author. More specifically, in 2009 the estimated number of records that did not report email address for corresponding author was $0.9 \%$ in biology, $3.6 \%$ in chemistry, $2.9 \%$ in earth and environmental sciences and $4.5 \%$ in materials science.

${ }^{6}$ China was initially included in the survey. However, a low response rate of less than $5 \%$ for a test sample of Chinese addresses suggested that respondents were either not receiving the invitation or had problems responding to the invitation. We thus decided not to survey researchers based in China.
} 
scientists as well as variations in response rates across countries. The overall response rate is $40.6 \%$; the high is $69.0 \%$ for Italy, the low is $30.3 \%$ for Germany; 11 countries have a response rate of between $35.0 \%$ and $45.0 \%$. The response rate, conditional on the respondent completing the survey, is $35.6 \%$. Reported response rates do not take into account undelivered invitations due to such things as an incorrect email address, retirement or death and consequently underestimate the response rate. Concerning the degree to which the sample of respondents is representative of the panel and consequently of the underlying populations, we perform a number of tests. These are reported in Annex A and show, at worst, very modest evidence of bias.

The main language of the survey is English. However, the questionnaire and the invitation emails were available in six other languages: French, German, Italian, Japanese, Portuguese and Spanish. The online questionnaire was developed through the platform Qualtrics ${ }^{\circledR}$. Each respondent received a customised questionnaire because some questions made direct reference to the title, year and journal of the person's own article included in the sample. In the discussion that follows we refer to this article as the survey article.

Through the survey we collected data on the survey article selected by the sampling criteria as well as information on background characteristics of the corresponding author. Concerning article-specific data we collected information on whether the article involved an international collaboration, a set of reported characteristics of the topic that the survey article addresses (e.g. whether it is in an emerging or multidisciplinary field and whether it is in a main research area for the author). With regard to the corresponding author, we collected a number of individual characteristics, including age, gender, job position, type of affiliation, international mobility data (including current country, country of origin, reasons for leaving the origin country, periods of education or work abroad) and type of initial entry in the host country (for master/bachelor, $\mathrm{PhD}$, Post-doc, direct employment). We also collected from respondents information on the their international network of research collaboration. More specifically, we asked the respondent the number of countries in the last 2 years with which the respondent had collaborations. In the case of foreign-born respondents, we also asked whether they have collaborations with researchers still based in their origin country and/or with researchers from their origin country who have migrated to a third country.

The GlobSci survey is one of the few datasets providing large-scale comparable data on the mobility of the academic workforce in a large number of countries. While micro-level data are available for migrants to OECD countries, they are not specific to the academic workforce (Docquier et al., 2009). For the academic workforce, data until now have been very limited. Three, however, are worth noting. The first is a survey of Career of Doctorate Holders (known as $\mathrm{CDH}$ ), conducted in seven countries by the OECD in collaboration with Eurostat and the UNESCO Institute for Statistics (UIS) (Auriol, 2007). The second (Ates et al., 2010) is a pilot study of Eurostat in all domains of science and humanities, called "The Eurodoc Survey I of doctoral candidates" conducted in 2008-2009 in twelve European countries (Austria, Belgium, Croatia, Finland, France, Germany, the Netherlands, Norway, Portugal, Slovenia, Spain and Sweden). The third is a pilot study of EU-US mobility designed to be used in combination with the Eurostat project (IdeaConsult, 2010). Low response rates in the latter two studies (below $10 \%)$ make these data unreliable for research purposes.

In the following sections 3.2 and 3.3 we present summary statistics on international mobility patterns and on the relationship between researchers' mobility status and international research networks. For a comprehensive discussion of summary statistics about the international mobility patterns through the GlobSci dataset we refer the reader to Franzoni et al. (2012). 


\subsection{Evidence on international mobility patterns}

Country of origin was determined in the survey by asking the corresponding author to report country of residence at age 18 and the country of residence in 2011. We prefer to use country of residence at age 18 to country of birth because we are interested in mobility decisions occurring for reasons of work or study of the respondents. Relocation events occurring before the age of 18 likely reflect parental decisions rather than choices of the respondent ${ }^{7}$. Although we do not take country of birth as a reference, in the following description respondents residing in the same country as they did at age 18 are referred to as "natives;" those residing in a different country than where they lived at age 18 are referred to as "foreign born."

Data for the scientists for whom country of origin and country of residence in 2011 could be determined are summarized in Table 1 and show considerable variation in the percent foreign born working or studying in country ${ }^{8}$. Switzerland heads the list. More than one out of two scientists studying or working in Switzerland in 2011 lived abroad at age 18. Canada is a distant second, being 9.8 percentage points lower, followed closely by Australia (44.5\%), and then by the United States with 38.4\% and Sweden with 37.6\%. A number of countries have an extremely low percent of foreign scientists studying or working in the country. Particularly notable is the virtual absence of foreign scientists studying or working in India, followed closely by Italy with $3.0 \%$, Japan with $5.0 \%$, Brazil with $7.1 \%$ and Spain with $7.3 \%$.

Table 1 International mobility patterns of surveyed scientists by country of work or study in 2011.

\begin{tabular}{lcl}
\hline $\begin{array}{l}\text { Country of work or } \\
\text { study in 2011 }\end{array}$ & $\begin{array}{c}\text { Incidence of foreign } \\
\text { born (\%) }\end{array}$ & $\begin{array}{l}\text { Countries supplying 10\% or more } \\
\text { of foreign workforce }\end{array}$ \\
\hline Australia & 44.5 & UK (21.1) China (12.5) \\
Belgium & 18.2 & Germany (15.2) France (15.2) Italy (13.0) \\
Brazil & 7.1 & Argentina (16.0) France (14.0) Columbia (12.0) Peru (12.0) \\
Canada & 46.9 & UK (13.5) U.S (13.5) China (10.9) \\
Denmark & 21.8 & Germany (24.4) \\
France & 17.3 & Italy (13.8) \\
Germany & 23.2 & None \\
India & 0.8 & Data are not reported due to small numbers. \\
Italy & 3.0 & France (13.0) Germany (11.1) Spain (11.1) \\
Japan & 5.0 & China (33.7) South Korea (11.6) \\
Netherlands & 27.7 & Germany (14.6) Italy (12.5) \\
Spain & 7.3 & Argentina (12.6) France (10.3) Italy (10.3) \\
Sweden & 37.6 & Germany (11.9) Russian Fed. (10.2) \\
Switzerland & 56.7 & Germany (36.9) \\
UK & 32.9 & Germany (15.2) Italy (10.4) \\
U.S. & 38.4 & China (16.9) India (12.3) \\
\hline Source: & $2012)$ Forign Born Scientists: Mobilit) Patterns for Sixteen Counties, Nature
\end{tabular}

Source: Adapted from Franzoni et al. (2012) Foreign Born Scientists: Mobility Patterns for Sixteen Countries, Nature Biotechnology, 30(12) pp. 1250-1253.

\footnotetext{
${ }^{7}$ We have also collected data on country of birth and migration activity before age 18 . We use information regarding international mobility during childhood as a control for endogenity of mobility and research performance in Franzoni et al. (2014). We exploit migration during childhood also in this paper to control for possible endogenity biases in a specific model specification.

${ }^{8}$ See annex A for details on country panel size.
} 
Countries also vary in the degree of diversity of immigrants who work in country, measured by the percentage of immigrant researchers from the top source countries. Switzerland, which shows the highest incidence of foreign born also has a very high concentration of inflows due to the substantial migration of researchers from Germany. Other countries, such as the UK, show a more diversified composition of source countries. The aggregated statistics reported above for the country level are computed using all collected observations for which information regarding country of origin and country of residence in 2011 was available. In the following summary statistics and in the subsequent econometric analysis we will focus exclusively on the subset of surveyed scientists working in academia or at a public research institution at the time of the survey, dropping respondents whose main affiliation in 2011 was with a company.

\subsection{Mobility and the scope of international research networks}

In the analysis that follows, surveyed researchers are classified into one of three possible international mobility statuses with respect to her/his country of residence in 2011: i) foreign born $(23.1 \%$ of the sample); ii) returnee after one or more periods abroad for a $\mathrm{PhD}$, a postdoc or employment $(29.9 \%)$; iii) nonmigrant natives $(47.0 \%)$. Based on the survey data, we derive two measures of the individual's propensity to have an international research network using two alternative types of information: i) the number of countries with which the scientist reported having one or more collaborations in the past two years ii) characteristics of the survey paper in terms of whether it shows an international co-authorship. Table 2 presents self-reported data concerning the number of countries with which the scientist reported having collaborations in the past two years. We see that nonmigrant researchers show on average the highest incidence of no international collaboration or minimal international collaboration (with 1 country). Conversely, both foreign-born and returnees consistently show the highest incidence of collaboration with researchers in two or more countries. Clearly, such patterns are likely affected by field specificities that will be accounted for in the econometric section.

Table 2 - Size of the international research network related to the activities in the past two years by international mobility status of respondents.

\begin{tabular}{lcccc}
\hline & \multicolumn{3}{c}{ International network size (\% of respondents) } \\
\cline { 2 - 5 } & Full Sample & Foreign born & Returnees & Nonmigrant \\
\hline No international collaborations & 19.08 & 14.06 & 14.26 & 24.36 \\
Small network (1 country) & 18.71 & 17.59 & 17.28 & 19.91 \\
Medium network (2 to 4 countries) & 43.69 & 47.53 & 47.02 & 40.02 \\
Large network (more than 4 countries) & 18.53 & 20.82 & 21.45 & 15.72 \\
\hline
\end{tabular}

Table 3 - Incidence of internationally co-authored papers by scientific field and international mobility status of corresponding author.

\begin{tabular}{lccccc}
\hline & \multicolumn{3}{c}{ Incidence of international collaborations on the survey article } \\
\cline { 2 - 5 } & All fields & Biology & Chemistry & Earth Science & $\begin{array}{c}\text { Materials } \\
\text { Science }\end{array}$ \\
\hline Full Sample & & & & & $22.82 \%$ \\
Foreign born & $23.94 \%$ & $25.30 \%$ & $23.61 \%$ & $33.17 \%$ & $30.01 \%$ \\
Returnees & $33.59 \%$ & $30.52 \%$ & $31.66 \%$ & $42.68 \%$ & $24.18 \%$ \\
Nonmigrant & $29.12 \%$ & $28.85 \%$ & $26.38 \%$ & $43.23 \%$ & $18.15 \%$ \\
\hline
\end{tabular}


Table 3 provides information regarding the incidence of researchers who are corresponding authors of a survey paper with one or more international co-authors, by mobility status. The data show that about $24 \%$ of the articles in our dataset involved an international collaboration, although there is some variance across the four disciplines. In all fields the incidence of internationally co-authored papers is lower for nonmigrant researchers. Note that the summary statistics reported in Table 2 and Table 3 do not account for additional factors (e.g. age, type of affiliation, country of origin and residence of respondents) that are likely to affect the propensity to engage in international collaboration. We will address such factors in detail in the section devoted to the econometric analyses.

In order to further investigate the link between international collaboration and international mobility, we present data in Table 4 concerning the incidence, by country of current work or study, of foreign born who declare having a research collaboration with researchers located in their origin country (columns I and II) or with researchers from the same origin country who migrated to a third country (column III). By way of example, $46.1 \%$ of foreign born researchers in Australia report that they have an international collaboration with someone currently based in their home country. Of these, $42.6 \%$ of natives from noncore countries (such as China) report collaboration with someone in their country of origin. Interestingly, on average slightly more than $40 \%$ of foreign-born researchers report research collaborations with researchers in their countries of origin. The incidence of collaboration with individuals in the origin country tends to decrease when we focus exclusively on foreign born researchers from noncore countries (column II). There are, however, important exceptions: in the case of US, which attracts a large number of researchers from China and India, we observe a relatively smaller reduction in the percentage when we restrict the analysis to foreign natives of noncore countries only and in the case of Brazil and Italy we actually see an increase. The data also allow us to analyze the relationship between international mobility and research networks by looking at the propensity of foreign born scientists to have a collaboration with researchers from their country of origin who have moved to a third country (Table 4, column III). The aim is to capture a diaspora effect behind the higher collaboration propensity of foreign born. The data reveal that a non negligible share of foreign born collaborate with a community of expatriates from their origin country: on average $19.3 \%$, with a minimum of $11.3 \%$ for foreign born who are currently working in Japan and a maximum of $33.3 \%$ for foreign born currently working in Denmark. 
Table 4 Percentage of foreign born researchers, by country of work or study in year 2011, who report collaboration with other researchers currently based in their country of origin (I and II) and with other researchers from the same origin country who have emigrated (III).

\begin{tabular}{lccc}
\hline & $\begin{array}{c}\text { Percentage of foreign born researchers } \\
\text { who collaborate with nationals in the } \\
\text { origin country }\end{array}$ & $\begin{array}{c}\text { Percentage of foreign born researchers } \\
\text { who collaborate with nationals who have } \\
\text { migrated to a different country }\end{array}$ \\
\hline Current country & I & II & III \\
\hline Australia & From origin & $\begin{array}{c}\text { From noncore } \\
\text { origin countries* }\end{array}$ & $\begin{array}{c}\text { From any origin } \\
\text { country }\end{array}$ \\
Belgium & 46.1 & 42.6 & 26.29 \\
Brazil & 55.6 & 16.7 & 22.86 \\
Canada & 29.3 & 34.5 & 12.20 \\
Denmark & 35.8 & 27.5 & 19.44 \\
France & 33.3 & 27.3 & 33.33 \\
Germany & 57.7 & 48.9 & 17.91 \\
Italy & 39.0 & 35.7 & 17.84 \\
Japan & 56.8 & 63.2 & 20.45 \\
Netherlands & 43.5 & 39.6 & 11.29 \\
Spain & 53.4 & 40.0 & 28.77 \\
Sweden & 38.0 & 28.6 & 18.31 \\
Switzerland & 56.7 & 44.7 & 17.78 \\
UK & 50.3 & 39.3 & 26.38 \\
USA & 44.0 & 34.0 & 21.87 \\
TOT & 37.4 & 35.1 & 16.96 \\
\hline F & 41.7 & 35.9 & 19.29 \\
\hline
\end{tabular}

* Core countries are those appearing in the table; noncore are all others.

\section{ECONOMETRIC ANALYSES}

This section presents a set of econometric models that investigate the presence of a correlation at the individual level between international mobility and the scope of international research networks. We assess such relationships controlling for researchers background, scientific fields and country of residence. In particular, we analyze the correlation between international mobility status and the scope of the respondent's international research network, measured by whether the respondent reported collaborating with individuals living outside the current country of work or study in the past 2 years. For this purpose, we have created the discrete ordered variable NETWORK SIZE which takes the value of 1 for those with no international collaborations in the past 2 years, 2 for those with collaborations in just one other country, 3 for those with collaborations in two to four countries and 4 for those with collaborations in 5 or more countries. These levels of the ordered discrete dependent variable correspond to the thresholds used in the previous summary statistics to identify respectively no international network, small network, medium network and large network. The measures of international scope of the research network are self-reported by respondents of the survey.

Our models include a set of author-specific characteristics. In particular we control for: age (AGE), a dummy variable for gender (FEMALE), a dummy variable for whether the respondent has a job position that allows full research independence, i.e. professorship (INDEPENDENT), a self-reported indicator on a 1-5 scale of the average importance of research collaboration in the specific scientific sub-field of the respondent (IMPORTANCE OF COLLAB).

We also include in all model specifications a set of four dummies for the broad scientific field of the respondent (Biology, Chemistry, Earth Science, Material Science), a set of three institution dummies (University, Public Research Institution, other nonprofit institutions) and a set of 16 
country dummies (related to the country of residence of the respondent when the survey was filled in). With regard to the international mobility status of the respondent, we have defined three dummy variables FOREIGN BORN, RETURNED, and NONMIGRANT. The latter is the omitted variable in all model specifications. The dummy variable RETURNED equals one for those researchers who declared having spent time abroad for $\mathrm{PhD}$ study, a postdoc position or a job and have returned to the origin country at the time the questionnaire was filled out.

In order to better assess the relationship between migration and international research networks we also have constructed a set of variables that identify subgroups of foreign born along different dimensions. The goal is to identify actual drivers of an above/below average collaboration premium of foreign born researchers. We summarize the different subgroups below. In all the model specification in which we use the dummy variables which split foreign born into subgroups, the omitted variable will be again nonmigrant natives (NONMIGRANT).

Scientific level of the origin country relative to that of the destination country: In this case we split foreign born between those coming from countries with a higher or lower $\mathrm{H}$-index relative to the $\mathrm{H}$-index of the destination country. The country level $\mathrm{H}$-index has been collected through the Scimago website and is based, for each country, on the scientific production over the years 1996-2010. The indicator represents an aggregated measure of the scientific standing of the country. The dummy variable HIGHER HINDEX takes the value of one for those foreign born whose origin country has a higher $\mathrm{H}$-index than that of the destination country. The dummy variable LOWER HINDEX takes the value of one for those foreign born whose origin country has a lower H-index than that of the destination country.

Timing of entry into the destination country: We split foreign-born between those who initially entered the destination country for bachelor or master's degree study, the $\mathrm{PhD}$, a postdoc position, or a job. The related dummy variables are ENTRY BA_MA, ENTRY PHD, ENTRY POSTDOC, ENTRY JOB. This set of dummies provides a univocal classification of all the foreign born in the sample.

National link: We split foreign born between those who declare/do not declare having an ongoing research collaboration with other researchers who share a common national link. We consider a national link to be a collaboration that occurs either with researchers from the same origin country who are currently expatriates in a country different than the country where the respondent is located (the diaspora network), or with researchers based in the origin country of the respondent (the country of origin network). The related dummy variables are NATIONAL COLLAB and NO NATIONAL COLLAB. Ideally we would like to further differentiate between migrants who collaborate with the diaspora vs. those who collaborate with individuals in their home country. Such a partition, however, is not possible because a number of migrants in the survey report collaborating with expats as well as with individuals working in their home country. As a result, and in order to deepen our understanding, we divide the two components of the national links variable into two separate subsets.

Link to the diaspora network: We split foreign-born between those who declare/do not declare having ongoing research collaborations with other researchers from their same origin country who have migrated to a third country. The related dummy variable COLLAB DIASPORA takes the value of one for those foreign born who declare having collaborations with at least 1 country and who also declare having research collaborations with researchers from their origin country who moved to a third country. The dummy variable COLLAB NO DIASPORA takes the value of one for those foreign born who declare having collaborations with at least 1 country and who

\footnotetext{
${ }^{9}$ Source: Scimago Journal and Country Rank. Retrieved from http://www.scimagojr.com on April 18, 2012
} 
declare having no research collaborations with researchers from their origin country who moved to a third country.

Link to the country of origin: We split foreign born between those who declare/do not declare having research collaborations with other researchers based in their country of origin. The related dummy variable COLLAB ORIGIN takes the value of one for those foreign born who declare having collaborations with at least 1 country and who also declare having research collaborations with researchers based in their origin country. The dummy variable COLLAB NO ORIGIN takes the value of one for those foreign born who declare having collaborations with at least 1 country and who also declare having no research collaborations with researchers based in their origin country.

All the dummies that split the foreign born according to the characteristics of their collaborations (either related to national links, diaspora effects, or link to the country of origin) are used in model specifications in which we exclude researchers who, irrespective of mobility status, declare having no international research collaborations in the past 2 years.

In section 4.1 we show the results of the analysis of the effects of mobility status on the scope of international research network based on a set of ordered probit models. In section 4.2 we present as a robustness check a set of models in which we test the correlation between mobility status and international collaboration propensity by using information from the survey article rather than self-declared network size. In particular, we analyse the correlation between the mobility status of the respondent and the likelihood that the survey paper is internationally co-authored. For this purpose we have created a dummy variable named INTERN CO-AUTHORED that equals one for those survey articles in our sample that have an international network of coauthors. In this set of models we control also for the following article-specific variables: number of co-authors (SIZE), whether the respondent reports the article to be in her/his main research area on a 1-5 scale (CORE PROJ). Table 5 provides the summary statistics of the variables used in the econometric models.

Table 5 summary statistics of variables used in the econometric analyses

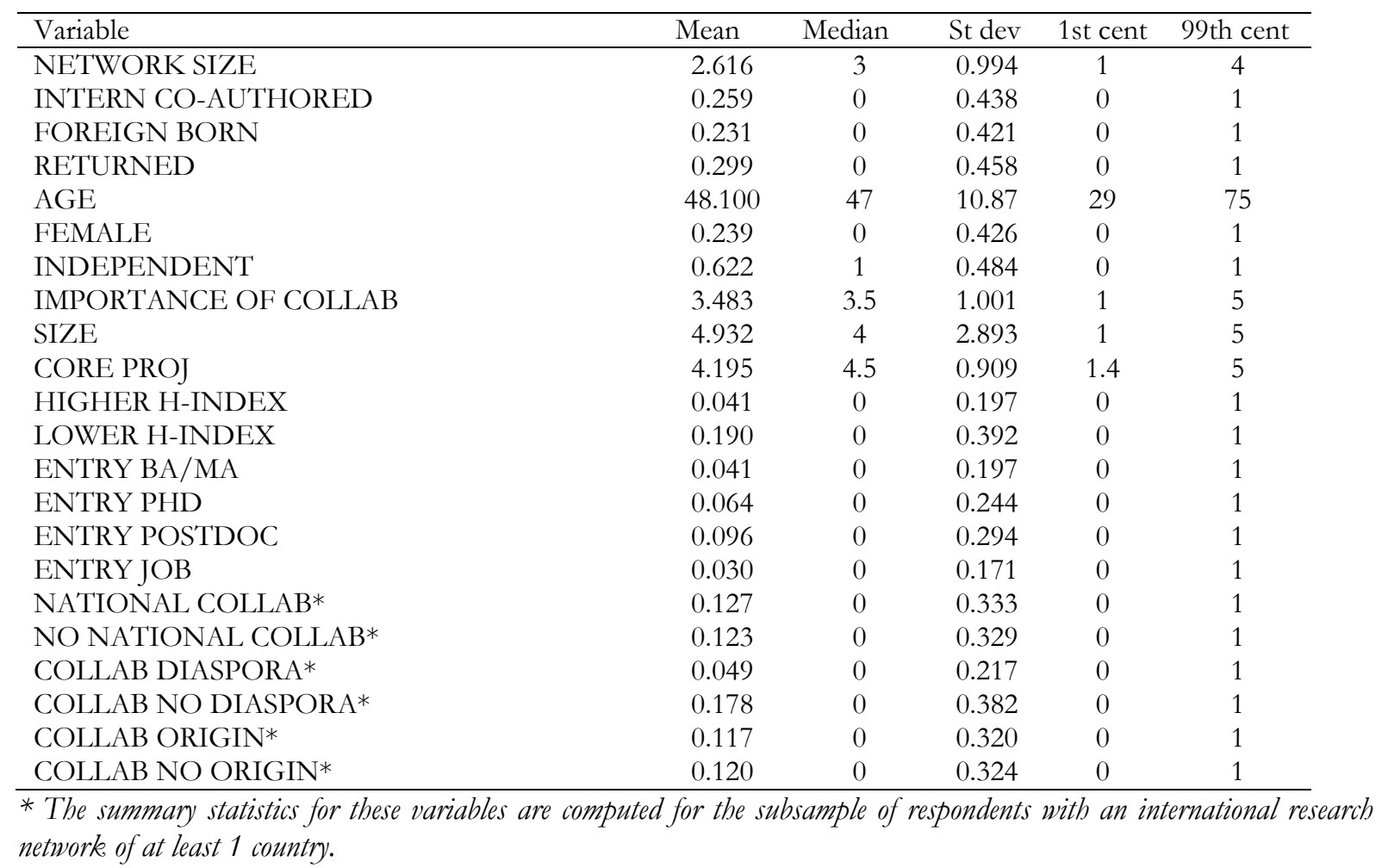




\subsection{International mobility status and the scope of the international research network}

Table 7 presents results of an ordered probit model testing for the presence of significant correlations at the individual level between the mobility status and the size of the international network of scientific collaboration of respondents. In model I we show the baseline specification while in models II and III we test for the additional impact exerted by the mobility status of the respondent. In these latter model specifications the omitted mobility status dummy is the nonmigrant researchers. Hence, the variables FOREIGN BORN and RETURNED estimate differentials in the scope of the international networks of these classes of researchers with respect to local nonmigrant natives, net of country and field effects and other individual level controls. As expected, in all model specifications both age and the variable capturing job independence have a positive significant effect on the scope of the international research network. Of more importance to this research is that the foreign-born variable shows a significant effect (Model II) and a higher impact than the returned effect in model III. The computation of marginal effects for specific outcomes of the rank ordered dependent variable NETWORK SIZE reveals that foreign born have, ceteris paribus, a 7.12\% higher likelihood of having a large research network (more than 4 countries) than natives nonmigrant. The same marginal effect is $5.5 \%$ for returnees and the larger network scope of foreign born vs. returnees is statistically significant at $99 \%$ level.

In Model IV we adopt an instrumental variables approach. This is motivated by the fact that the unobservable ability of individuals can be correlated both to migration and scientific performance. Individuals of higher quality might more likely be approached by colleagues for establishing collaborations at international level and may also be more likely to migrate. In order to address this problem of endogeneity, we choose to instrument the variable FOREIGN BORN with migration events that occurred during childhood (Franzoni et al. 2014). We expect mobility during childhood to be correlated to migration decisions in adult life because prior experience of relocation makes one more open to relocation opportunities, more able to overcome cultural shocks, et cetera associated with international mobility. At the same time, migration during childhood is arguably not affected by individual performance, because relocation events occurring before the age of 18 likely reflect parental decisions, rather than choices of the respondent. ${ }^{10}$ Results for Model IV confirm the presence of a significant collaboration premium of foreign born, even after accounting for individual characteristics related to migration, although with a larger confidence interval.

\footnotetext{
${ }^{10}$ Scientists who migrated during childhood are coded from the whole dataset as those reporting a country of birth different from the country of residence at age 18. Correlation of the dummy variable Child Migration with FOREIGN BORN=0.19***. Summary statistics of the dummy variable Child Migration: Mean=0.05; St.dev. $=0.22$. The ordered probit model with instrumental variables has been estimated with the CMP routine of STATA 12 which implements a recursive mixed process estimator developed by Roodman (2011).
} 
Table 6 - Ordered probit model on international network size (Baseline models I-III). Instrumental variable ordered probit model (model IV). Dependent variable NETWORK SIZE.

\begin{tabular}{|c|c|c|c|c|}
\hline MODELS & I & II & III & IV \\
\hline \multirow[t]{2}{*}{ FOREIGN BORN } & & $0.204^{* * *}$ & $0.278^{* * *}$ & $0.263^{*}$ \\
\hline & & $(0.023)$ & $(0.024)$ & $(0.142)$ \\
\hline \multirow[t]{2}{*}{ RETURNED } & & & $0.223^{* * *}$ & $0.223^{* * *}$ \\
\hline & & & $(0.022)$ & $(0.022)$ \\
\hline \multirow[t]{2}{*}{ AGE } & $0.007 * * *$ & $0.007 * * *$ & $0.007 * * *$ & $0.007 * * *$ \\
\hline & $(0.001)$ & $(0.001)$ & $(0.001)$ & $(0.001)$ \\
\hline \multirow[t]{2}{*}{ INDEPENDENT } & $0.308^{* * *}$ & $0.321 * * *$ & $0.302^{* * *}$ & $0.302 * * *$ \\
\hline & $(0.025)$ & $(0.025)$ & $(0.025)$ & $(0.025)$ \\
\hline \multirow[t]{2}{*}{ FEMALE } & $-0.225^{* * *}$ & $-0.223^{* * *}$ & $-0.214^{* * *}$ & $-0.214 * * *$ \\
\hline & $(0.022)$ & $(0.022)$ & $(0.022)$ & $(0.022)$ \\
\hline \multirow[t]{2}{*}{ IMPORTANCE OF COLLAB } & $0.181^{* * *}$ & $0.180^{* * *}$ & $0.183^{* * *}$ & $0.183^{* * *}$ \\
\hline & $(0.009)$ & $(0.009)$ & $(0.009)$ & $(0.009)$ \\
\hline Institution dummy & Yes & Yes & Yes & Yes \\
\hline Current Country dummies & Yes & Yes & Yes & Yes \\
\hline Field dummies & Yes & Yes & Yes & Yes \\
\hline \multirow[t]{2}{*}{ Constant cut1 } & $0.492^{* * *}$ & $0.613^{* * *}$ & $0.612^{* * *}$ & $0.608^{* * *}$ \\
\hline & $(0.073)$ & $(0.074)$ & $(0.074)$ & $(0.081)$ \\
\hline \multirow[t]{2}{*}{ Constant cut 2} & $1.120^{* * *}$ & $1.243^{* * *}$ & $1.246^{* * *}$ & $1.242^{* * *}$ \\
\hline & $(0.073)$ & $(0.074)$ & $(0.074)$ & $(0.081)$ \\
\hline \multirow[t]{2}{*}{ Constant cut 3} & $2.492^{* * *}$ & $2.618^{* * *}$ & $2.626 * * *$ & $2.622^{* * *}$ \\
\hline & $(0.074)$ & $(0.076)$ & $(0.076)$ & $(0.083)$ \\
\hline Observations & 15,109 & 15,109 & 15,109 & 15,109 \\
\hline Pseudo R-sq & 0.0772 & 0.0791 & 0.0817 & - \\
\hline Log Lik & -18148.4 & -18109.8 & -18058.9 & -26421.5 \\
\hline Chi-Sq & 3035.1 & 3112.3 & 3214.2 & 3184.5 \\
\hline
\end{tabular}

Because the average estimated differentials between nonmigrant researchers, foreign born and returnees in collaboration propensity might be affected by the specific conditions of the destination country, we have estimated Model III in Table 6 for specific subsets of the 16 destination countries (grouped as: USA, Europe and Other countries). Results are reported in Annex B and confirm the presence of a positive and significant collaboration premium for the foreign born in each of the destination country subsets. 
Table 7 - Ordered probit model on international network size. Foreign born split in subgroups. Relative scientific level of origin and destination country (Model I); Type of entry effects (Model II).

\begin{tabular}{|c|c|c|}
\hline Models & $\mathbf{I}$ & II \\
\hline HIGHER H-INDEX & $\begin{array}{c}0.366^{* * *} \\
(0.051)\end{array}$ & \\
\hline LOWER H-INDEX & $\begin{array}{c}0.260 * * * \\
(0.026)\end{array}$ & \\
\hline ENTRY BA_MA & & $\begin{array}{c}0.174 * * * \\
(0.047)\end{array}$ \\
\hline ENTRY PHD & & $\begin{array}{c}0.159 * * * \\
(0.040)\end{array}$ \\
\hline ENTRY POSTDOC & & $\begin{array}{c}0.349^{* * *} \\
(0.033)\end{array}$ \\
\hline ENTRY JOB & & $\begin{array}{c}0.460 * * * \\
(0.057)\end{array}$ \\
\hline RETURNED & $\begin{array}{c}0.226^{* * *} \\
(0.022)\end{array}$ & $\begin{array}{c}0.227 * * * \\
(0.022)\end{array}$ \\
\hline AGE & $\begin{array}{c}0.007^{* * *} \\
(0.001)\end{array}$ & $\begin{array}{c}0.006^{* * *} \\
(0.001)\end{array}$ \\
\hline INDEPENDENT & $\begin{array}{c}0.230 * * * \\
(0.025)\end{array}$ & $\begin{array}{c}0.297 * * * \\
(0.025)\end{array}$ \\
\hline FEMALE & $\begin{array}{c}-0.215^{* * *} \\
(0.022)\end{array}$ & $\begin{array}{c}-0.213^{* * *} \\
(0.022)\end{array}$ \\
\hline IMPORTANCE OF COLLAB & $\begin{array}{c}0.183^{* * *} \\
(0.009)\end{array}$ & $\begin{array}{c}0.183^{* * *} \\
(0.009)\end{array}$ \\
\hline Institution dummy & Yes & Yes \\
\hline Current country dummies & Yes & Yes \\
\hline Field dummies & Yes & Yes \\
\hline Constant cut1 & $\begin{array}{c}0.601 * * * \\
(0.074)\end{array}$ & $\begin{array}{c}0.587 * * * \\
(0.074)\end{array}$ \\
\hline Constant cut 2 & $\begin{array}{c}1.234^{* * *} \\
(0.075)\end{array}$ & $\begin{array}{c}1.222^{* * *} \\
(0.074)\end{array}$ \\
\hline Constant cut 3 & $\begin{array}{c}2.615^{* * *} \\
(0.076)\end{array}$ & $\begin{array}{c}2.604^{* * *} \\
(0.076)\end{array}$ \\
\hline Observations & 15,109 & 15,109 \\
\hline Pseudo R-sq & 0.082 & 0.083 \\
\hline Log Lik & -18056.9 & -18042.3 \\
\hline Chi-Sq & 3218.1 & 3247.4 \\
\hline
\end{tabular}

In the models presented in Table 7 we further analyse the relationship between international mobility status and international collaboration. In these model specifications the omitted mobility status dummy remains the nonmigrant researchers. Given the important role that knowledge, embedded in social capital, plays in collaboration we first examine whether collaborations are more likely among migrants from countries with relatively strong science bases. In Model I we look at this issue by differentiating the foreign born between those coming from an origin country with a higher $\mathrm{H}$-index from those coming from an origin country with a lower $\mathrm{H}$-index than the current destination country. Results indicate the presence of differentiated effects for the subsamples of foreign born. The foreign born who come from a country with a relative 
higher scientific level outperform the local nonmigrant. For this subgroup of foreign born we estimate a marginal effect of $10.1 \%$ on the likelihood of having a large research network, which is also significantly larger than the marginal network effect for returnees. On the contrary, foreign born from countries with a lower $\mathrm{H}$-index do not significantly outperform returnees although they do significantly outperform native nonmigrant researchers. We also find their network performance to be significantly lower than that of migrants from higher $\mathrm{H}$-index countries. We conclude that, compared to the nonmigrant, the network effect is stronger in magnitude for foreign-born coming from countries with relatively higher $\mathrm{H}$-index than the host country, but in both cases the foreign-born hold a network premium over the nonmigrant.

In Model II, we split foreign born researchers into groups based on the timing of their entry into the destination country. The idea behind this division of foreign born is that foreign born who have been trained in the destination country should have limited "international" social capital (e.g. no previous research networks abroad established during their training and research career) compared to the foreign born who trained outside the country before entering or worked outside the country before entering. As expected, we find evidence of a moderating effect of training in the destination country on the outperformance of foreign born in terms of international networking. The results suggest that the aggregated "foreigner premium" effect is driven mostly by migrant researchers with previous training or work experience outside of the destination country, i.e. by individuals who had likely formed a rich knowledge network prior to entering the destination country. Immigrants for a postdoc represent a clear example of this typology of researchers. Our findings are consistent with the idea that at the time of migration senior scientists have more social capital with older-established scholars than do scientists who migrate early in the training process.

In table 8 we investigate the role of national links. Here we split the foreign born according to whether they indicate having ongoing research collaborations with researchers who are part of the same national community. The model specifications reported in Table 8 are applied to a restricted sample in which we exclude researchers with no international collaborations irrespective of their international mobility status. We do so in order to avoid spurious correlations of the dependent variable with the regressors that split the foreign born. Hence, in these models we use a new ordinal dependent variable with only 3 levels: NEWTORK SIZE2 takes the value of 1 for those researchers with collaborations with just one other country, 2 for those with collaborations with two to four countries and 3 for those with collaboration in 5 or more countries). Results of Model I suggest that among scientists who have international collaborations the larger propensity of foreign-born scholars to cooperate with more countries, compared to the propensity of nonmigrant scientists, is explained by national links, be they links with the home country or with researchers from the home country who are currently working in a third country (NATIONAL COLLAB). Foreign-born scientists who do not indicate links with researchers in the home country or with expats in a third country (NO NATIONAL COLLAB) behave no differently than nonmigrant scientists in terms of the scope of their international networks and have significantly fewer networks than those who collaborate with scientists who share the same country of origin. 
Table 8 - Ordered probit model on international network size. Models restricted to respondents with an international collaboration network of at least one country. Dependent variable: NEWTORK SIZE2. Foreign born splitted in subgroups. Models analyzing: National links (I); Diaspora effects (II); Link to the origin country (III).

\begin{tabular}{|c|c|c|c|}
\hline Models & I & II & II \\
\hline NATIONAL COLLAB & $\begin{array}{c}0.406^{* * *} \\
(0.034)\end{array}$ & & \\
\hline NO NATIONAL COLLAB & $\begin{array}{l}-0.049 \\
(0.035)\end{array}$ & & \\
\hline COLLAB DIASPORA & & $\begin{array}{c}0.574 * * * \\
(0.051)\end{array}$ & \\
\hline COLLAB NO DIASPORA & & $\begin{array}{c}0.096^{* * *} \\
(0.031)\end{array}$ & \\
\hline COLLAB ORIGIN & & & $\begin{array}{c}0.433^{* * *} \\
(0.035)\end{array}$ \\
\hline COLLAB NO ORIGIN & & & $\begin{array}{l}-0.037 \\
(0.036)\end{array}$ \\
\hline RETURNED & $\begin{array}{c}0.109^{* * *} \\
(0.025)\end{array}$ & $\begin{array}{c}0.123^{* * *} \\
(0.025)\end{array}$ & $\begin{array}{c}0.109 * * * \\
(0.025)\end{array}$ \\
\hline AGE & $\begin{array}{c}0.009 * * * \\
(0.001)\end{array}$ & $\begin{array}{c}0.010^{* * *} \\
(0.001)\end{array}$ & $\begin{array}{c}0.009^{* * *} \\
(0.001)\end{array}$ \\
\hline INDEPENDENT & $\begin{array}{c}0.226^{* * *} \\
(0.029)\end{array}$ & $\begin{array}{c}0.216^{* * *} \\
(0.029)\end{array}$ & $\begin{array}{c}0.213^{* * *} \\
(0.029)\end{array}$ \\
\hline FEMALE & $\begin{array}{c}-0.180^{* * *} \\
(0.025)\end{array}$ & $\begin{array}{c}-0.184^{* * *} \\
(0.025)\end{array}$ & $\begin{array}{c}-0.184^{* * *} \\
(0.025)\end{array}$ \\
\hline IMPORTANCE OF COLLAB & $\begin{array}{c}0.153^{* * *} \\
(0.011)\end{array}$ & $\begin{array}{c}0.152^{* * *} \\
(0.011)\end{array}$ & $\begin{array}{c}0.153^{* * *} \\
(0.011)\end{array}$ \\
\hline Institution dummy & Yes & Yes & Yes \\
\hline Current country dummies & Yes & Yes & Yes \\
\hline Field dummies & Yes & Yes & Yes \\
\hline Constant cut1 & $\begin{array}{c}0.542^{* * *} \\
(0.088)\end{array}$ & $\begin{array}{c}0.560^{* * *} \\
(0.089)\end{array}$ & $\begin{array}{c}0.539 * * * \\
(0.089)\end{array}$ \\
\hline Constant cut 2 & $\begin{array}{c}2.176^{* * *} \\
(0.089)\end{array}$ & $\begin{array}{c}2.190^{* * *} \\
(0.090)\end{array}$ & $\begin{array}{c}2.172^{* * *} \\
(0.090)\end{array}$ \\
\hline Observations & 12,016 & 12,016 & 12,016 \\
\hline Pseudo R-sq & 0.073 & 0.072 & 0.074 \\
\hline Log Lik & -11409.8 & -11227.1 & -11207 \\
\hline Chi-Sq & 1801.5 & 1745.5 & 1785.5 \\
\hline
\end{tabular}

We further investigate this effect by assessing the impact of diaspora networks (Model II) from all other migrant networks, be they networks with the home country or networks with nonnationals in third countries. We find the marginal effect on the likelihood of having a network of collaborations larger than 4 countries in the past two years of the variable COLLAB DIASPORA to be $19.4 \%$. The variable capturing research collaborations with other than the diaspora network (COLLAB NO DIASPORA) is also positive and significant although significantly smaller than the COLLAB DIASPORA coefficient. The significant effect is likely caused by the inclusion of respondents who report collaborating only with same-nationals in the origin country in the COLLAB NO DIASPORA variable, and not with the inclusion of nonnationals abroad in 
the variable. ${ }^{11}$ The relatively small size of the coefficient is likely caused by the fact that the former group makes up a minority of those in this category. To investigate this further, in model III we differentiate the foreign born between those having links with scientists in the country of origin vs. those not having links with scientists in the country of origin regardless of whether they have diaspora network links. The variable COLLAB ORIGIN, capturing collaborations with scientists in the origin country, is highly significant. Interestingly, in Model III we find that those foreign born who do not have any research links with the origin country (COLLAB NO ORIGIN) tend to have no advantage in terms of network size compared to nonmigrant natives who collaborate internationally. In conclusion, we show that, among scholars who collaborate internationally, the advantage of foreign-born scholars over nonmigrant scholars is explained to a large extent by national links. Both the links with the origin country and with the diaspora network matter, but respondents who report no links to the origin country appear to have no formal advantage compared to the nonmigrant domestic scientists.

\subsection{Robustness checks}

In this section we analyse the link between collaboration propensity and international mobility status by observing whether the randomly selected survey paper of the respondent is internationally co-authored. We use the characteristics of the randomly selected survey paper for the following reasons. First, the original sample was constructed through a stratification of papers with reference to quality, based on the impact factor of the related journal within the subfield distribution of journals. Second, in the questionnaire we had a question which asked to report on a 1-5 scale whether the quality of the randomly selected article was lower/higher than the average scientific production of the respondent. The distribution of such variables reveals no biases among respondents in favour of papers with higher or lower quality. Third, the analysis of respondents versus nonrespondents reveals very limited responses bias related to the number of co-authors. ${ }^{12}$ We use a probit model specification in which the dependent variable (INTERN COAUTHORED) takes a value of one for those papers with an international co-authorship.

Results are reported in Table 9. The article-level controls, as expected, indicate in all models a positive effect of team size, with decreasing intensity, on the likelihood of observing an international collaboration. International collaborations appear to be more frequent among those articles that are in a main area of research interest of the author. Even after controlling for field and country dummies we observe that females are less likely to engage in international collaboration. On average older researchers are more likely to be involved in international collaborations. In model I we compare foreign-born and returnees to nonmigrant researchers working in the same country and scientific field. International mobility status variables indicate a positive and significant impact of both the foreign-born and the returnee variable. Hence, results based on the specific randomly selected survey article appear to confirm that - net of individual and article specific effects - mobile researchers have on average a higher propensity to be involved in international collaborations. The marginal effects at covariates' sample mean for model I indicate that being foreign born generates an increase, all else equal, of 13.8 percentage points in the likelihood of having an internationally co-authored paper. The marginal effects for the RETURNED variable in model I is $7.4 \%$; the estimated coefficient for the FOREIGN BORN variable is significantly higher $(99 \%$ confidence level) than the coefficient for the RETURNED variable. In model II in which we split foreign born according to their entry conditions, we obtain that marginal effects range from $8.8 \%$ for the variable ENTRY BA_MA to $19.1 \%$ for the

\footnotetext{
${ }^{11}$ Recall that because a number of migrants in the survey report collaborating with expats as well as individuals working in their home country we are unable to partition the NATIONAL COLLAB variable into an expat and nonexpat component.

${ }^{12}$ See Annex A for the analyses of response biases.
} 
variable ENTRY JOB. We find confirmation that the outperformance of foreign-born with respect to returnees is likely mostly driven by that subsample of foreign-born that entered as postdoc or directly for a job.

Table 9 - Robustness checks. Probit models. Dependent variable INTERN COAUTHORED equals one for those survey papers with an international co-authorship. Baseline model (I) and model based on the splitting of foreign according to the type of entry (II).

\begin{tabular}{|c|c|c|}
\hline Models & I & II \\
\hline FOREIGN BORN & $\begin{array}{c}0.422^{* * *} \\
(0.032)\end{array}$ & \\
\hline ENTRY BA_MA & & $\begin{array}{c}0.270^{* * *} \\
(0.063)\end{array}$ \\
\hline ENTRY PHD & & $\begin{array}{c}0.443^{* * *} \\
(0.052)\end{array}$ \\
\hline ENTRY POSTDOC & & $\begin{array}{c}0.433^{* * *} \\
(0.043)\end{array}$ \\
\hline ENTRY JOB & & $\begin{array}{c}0.545^{* * * *} \\
(0.070)\end{array}$ \\
\hline RETURNED & $\begin{array}{c}0.238^{* * *} \\
(0.029)\end{array}$ & $\begin{array}{c}0.240 * * * \\
(0.029)\end{array}$ \\
\hline SIZE & $\begin{array}{c}0.190^{* * *} \\
(0.008)\end{array}$ & $\begin{array}{c}0.190^{* * * *} \\
(0.008)\end{array}$ \\
\hline SIZE $^{2}$ & $\begin{array}{c}-0.004 * * * \\
(0.000)\end{array}$ & $\begin{array}{c}-0.004 * * * \\
(0.000)\end{array}$ \\
\hline CORE_PROJ & $\begin{array}{c}0.056^{* * *} \\
(0.013)\end{array}$ & $\begin{array}{c}0.056^{* * *} \\
(0.013)\end{array}$ \\
\hline AGE & $\begin{array}{c}0.003^{* *} \\
(0.001)\end{array}$ & $\begin{array}{c}0.003^{* *} \\
(0.001)\end{array}$ \\
\hline INDEPENDENT & $\begin{array}{l}0.0176 \\
(0.033)\end{array}$ & $\begin{array}{l}0.0144 \\
(0.033)\end{array}$ \\
\hline FEMALE & $\begin{array}{c}0.095^{* * *} \\
(0.029)\end{array}$ & $\begin{array}{c}-0.094^{* * *} \\
(0.029)\end{array}$ \\
\hline IMPORTANCE COLLAB & $\begin{array}{c}0.032^{* *} \\
(0.013)\end{array}$ & $\begin{array}{c}0.032^{* *} \\
(0.013)\end{array}$ \\
\hline Institution dummy & Yes & Yes \\
\hline Country dummies & Yes & Yes \\
\hline Field dummies & Yes & Yes \\
\hline Constant & $\begin{array}{c}-2.485^{* * *} \\
(0.116) \\
\end{array}$ & $\begin{array}{c}-2.472^{* * *} \\
(0.117) \\
\end{array}$ \\
\hline Observations & 14,458 & 14,458 \\
\hline Pseudo R-sq & 0.110 & 0.110 \\
\hline Log Lik & -7292.1 & -729 \\
\hline Chi-Sq & 1794.7 & 1805 \\
\hline
\end{tabular}

In all the econometric models presented sections 4.1 and 4.2 we have adopted a standard approach, which consists of dropping observations for which we were not able to collect all the 
required information in the survey ${ }^{13}$. Because such a procedure might generate possible biases in the estimates, and in order to check for robustness, we have run a set of additional models in which we account for missing data and introduce country-level weights that account for the variations in response rates across countries. Results of models that account for sample weights and imputed missing variables fully confirm the evidence reported in the paper ${ }^{14}$.

\section{CONCLUSIONS}

This paper contributes to an understanding of collaboration patterns of internationally mobile scientists working in four fields. Data are taken from the GlobSci survey that collected detailed data on the international mobility and scientific collaborations of researchers working or studying in 16 countries in 2011. Our summary evidence confirms the absolute relevance of the migration phenomenon for many advanced economies. More than $40 \%$ of the researchers sampled in the four fields studying or working in Switzerland, Canada and Australia are immigrants. The phenomenon is also nonnegligible for the US and for certain other European economies such as UK, Netherlands, Germany and Sweden.

Our research finds that migrants and returnees have larger international research networks than do native researchers who lack an international background. Such patterns hold across the sixteen countries as well as separately for the US, European countries and other countries. Second, the higher incidence of international collaboration among migrants is driven primarily by those who did not get their $\mathrm{PhD}$ in the destination country but rather came for a postdoctoral position or directly for employment at a university or public research centre in the destination country after doctoral training. Such results suggest that research links established during doctoral training by migrant researchers matter and are portable. It is consistent with the third finding that a sizeable share of foreign-born scientists (slightly more than 40\%) report research collaborations with researchers located in their country of origin. Moreover, and consistent with the portability concept, is the fourth finding that diaspora networks matter to the extent that migrants also collaborate with individuals from their home country who are studying or working in a third country. The portability concept is also consistent with the finding that returnees have larger international research networks than natives who lack an international experience. A fifth finding is that the size of a migrant's network correlates with the relative strength of the origin country's science base: those coming from countries with relatively stronger science bases have superior networks compared to those coming from relatively weaker countries.

Our research approach has several strengths. First, the homogeneity of the survey allows for direct comparisons, such as those made above, across countries regarding the inflow and outflow patterns of high-skilled people involved in scientific research. Second, we measure collaboration directly by asking the respondent about their collaborative experience, rather than relying on bibliometric measures of collaboration. By so doing, we are able to include "invisible colleges" in the measure of collaboration. Third, we have data on individual characteristics of the scientist as well as characteristics of the field of science. Fourth, by measuring collaboration patterns of the

\footnotetext{
${ }^{13}$ In particular some individual characteristics used in the econometric models (e.g. age and gender) were asked at the end of the questionnaire. As a result, there are 880 missing entries for gender and 1034 missing entries for age, mostly due to respondent dropouts.

${ }^{14}$ Concerning the imputation of missing values, we have imputed only the variables age and gender. The imputation procedure is based on the use of predicted values from a from a Logit model (for the FEMALE dummy variable) and of an OLS model (for AGE variable). The specifications used in the imputation models include among covariates country of residence in 2011, foreign experience (PhD, postdoc and job), job position, affiliation type, the presence of secondary affiliations, field of research. The data have been treated using the Multiple Imputation routine of STATA 12. Related econometric estimates are available from the authors upon request
} 
survey article we are able to check for the robustness of our findings. Fifth, we find our results robust to instrumenting for migration. This is important given that more able scientists may be more internationally mobile and more sought after as collaborators. Our approach, however, is not without limitations. Two are noted here. First, to the extent that migration happens because of international collaborations among teams, the relationship that we observe between mobility and collaboration may go the opposite way. The cross sectional nature of our data precludes our investigating this possibility. Second, and related, the cross sectional nature of our data precludes our ability to address the extent to which increased international mobility over time relates to increased patterns of collaboration.

In earlier work (Franzoni et al. 2014, Franzoni et al. 2012b) we find that migrants outperform natives who have returned after an international experience and natives who have returned outperform those who have never had an international experience. Our current research suggests that part of this performance premium is a result of the networks that migrants and returnees bring with them. Taken together these findings support the benefits that arise from programs designed to promote highly skilled immigration as well as programs that promote international experiences of natives. Policy initiatives that promote the formation of networks and leverage the strengths that networks provide include, but are not limited to, the following:

- The adoption of policies that facilitate the entrance of high skilled workers. In this regard, the EU has introduced the Blue Card program that makes it comparatively easier for tertiary educated to enter European Union and circulate among member countries, Canada and Australia have introduced a point system that gives preferential immigration treatment to individuals with a $\mathrm{PhD}$ and the US is considering stapling a Green Card to the diploma of $\mathrm{PhD}$ recipients who hold a temporary visa.

- Increased funding for programs that promote international experience, such as the Marie Curie and Erasmus programs.

- Providing opportunities from funding agencies to support the international mobility of researchers. This is a two-way street: countries can benefit by hosting international visitors as well as by providing funds for native researchers to work outside their country.

- Opening up national grants to the participation of foreign applicants who have established collaborations with domestic scientists.

Our research also suggests that researchers with international experiences could prove beneficial in the recruitment of colleagues. University administrators who are seeking to increase the international openness of their institutions or to recruit international faculties should bear this in mind in forming recruiting committees.

In conclusion, our results show that research networks are portable and that both returnees and migrants enhance the networks of countries where they work. We also find the networks of migrants to be highly populated by members of the diaspora. This finding, coupled with earlier findings that migration contributes to productivity (Franzoni et al., 2014), suggests that migration is not a zero sum game, in the sense that there are benefits for both the sending and the receiving countries. 


\section{References}

Ackers, L. 2008. Internationalisation, mobility and metrics: A new form of indirect discrimination? Minerva, 46, 411-435.

Ackers L., Gill B. 2008. Moving People and Knowledge: Scientific Mobility in an Enlarging European Union. Edward Elgar Publishing, London.

Adams, J.D., Black, G.C., Clemmons, J.R., Stephan, P.E. 2005. 2005. Scientific teams and institutional collaborations: Evidence from U.S. universities, 1981-1999. Research Policy. 34:259-285.

Agrawal, A., Cockburn, I., McHale, J. 2006. Gone but not forgotten: knowledge flows, labor mobility, and enduring social relationships. Journal of Economic Geography. 6:571-591.

Agrawal, A., Kapur, D., McHale, J., Oettl, A. 2011. Brain drain or brain bank? The impact of skilled emigration on poor-country innovation. Journal of Urban Economics. 69:43-55.

Almeida, P., Kogut, B. 1999. Localization of Knowledge and the Mobility of Engineers in Regional Networks. Management Science. 45(7):905-917.

Ates, G., Holländer, K., Koltcheva, N., Krstic, S., Parada F. 2013. The European Council of Doctoral Candidates and Junior Researchers. Eurodoc, Brussels, Belgium

Baruffaldi, S., Landoni, P. 2013. Return mobility and scientific productivity of researchers working abroad: The role of home country linkages. Research Policy. 41: 1655-1665

Crane, D. 1972. Invisible Colleges; Diffusion of knowledge in scientific communities. University of Chicago Press. Chicago.

Davenport, S. 2004. Panic and panacea: brain drain and science and technology human capital policy. Research Policy. 33:617-630.

de Solla Price, D. 1963. Little Science, Big Science. Columbia University Press. New York and London.

Defazio, D., Lockett, A., Wright, M. 2009. Funding incentives, collaborative dynamics and scientific productivity: Evidence from the EU framework program. Research Policy. 38:293-305.

Ding, W.W., Levin, S.G., Stephan, P.E., Winkler, A.E. 2010. The Impact of Information Technology on Academic Scientists' Productivity and Collaboration Patterns. Management Science. 56(9):1439-1461.

Docquier, F., Lowell, B.L., Marfouk, A. 2009. A gendered assessment of the brain Drain. Population and Development Review. 35(2):297-321.

European Science Foundation. 2013. New Concepts of Researcher Mobility: A comprehensive approach including combined / part-time positions. 49 Science Policy Briefing.

Fernandez-Zubieta, A., Geuna, A., Lawson, C. 2013. Researchers' mobility and its impact on scientific productivity. Working paper 06/2013 LEI \& BRICK, Università di Torino. 
Franzoni, C., Scellato, G., Stephan, P. 2012. Foreign Born Scientists: Mobility Patterns for Sixteen Countries. Nature Biotechnology. 30(12):1250-1253.

Franzoni, C., Scellato, G., Stephan, P. 2012 b. The mover's advantage: scientific performance of mobile academics. Working paper 18577. National Bureau of Economic Research, USA.

Franzoni, C., Scellato, G., Stephan, P. 2014. The mover's advantage: The superior performance of migrant scientists. Economics Letters, 122:89-93.

Furukawa, T., Shirakawa, N., Okuwada, K. 2011. Quantitative analysis of collaborative and mobility networks. Scientometrics. 87:451-466.

Gazni, A., Sugimoto, C.R., Didegah, F. 2012. Mapping World Scientific Collaboration: Authors, Institutions, and Countries. Journal of the American Society for Information Science and Technology. 63(2):323-335.

Georghiou, L. 1998. Global Cooperation in Research. Research Policy, 27, 611-626.

Gibson, J., McKenzie, D. 2012. The economic consequences of 'brain drain' of the best and brightest: microeconomic evidence from five countries. The Economic Journal. 122(560):339-375

Glanzel, W. 2001. National characteristics in international scientific co-authorship relations. Scientometrics. 51(1):69-115.

IdeaConsult 2010. Study on mobility patterns and career paths of EU researchers - MORE Project. Brussel, Belgium

Jöns, H. 2007. Transnational mobility and the spaces of knowledge production. A comparison of global patterns, motivations and collaborations in different academic fields. Social Geography, 2:97-114.

Jöns, H. 2009. 'Brain circulation' and transnational knowledge networks: Studying long-term effects of academic mobility to Germany, 1954-2000. Global Networks, 9(3):315-338

Jones, B.F., Wuchty, S., Uzzi, B. 2008. Geography, and Stratification in Science. Multi-University Research Teams: Shifting Impact. Science. 322:1259-1262.

Jonkers, K., Cruz-Castro, L. 2013. Research upon return: The effect of international mobility on scientific ties, production and impact. Research Policy. 42:1366- 1377.

Jonkers, K., Tijssen, R., 2008. Chinese researchers returning home: impacts of international mobility on research collaboration and scientific productivity. Scientometrics. 77(2):309-333.

Kahn, S., MacGarvie, M. 2011. The Effects of the Foreign Fulbright Program on Knowledge Creation in Science and Engineering. NBER Chapters, in: The Rate and Direction of Inventive Activity Revisited, pages 161-197 National Bureau of Economic Research, Inc.

Katz, J.S., Martin, B.R. 1997. What is research collaboration? Research Policy. 26:1-18.

Kerr, W. 2008. Ethnic scientific communities and international technology diffusion. The Review of Economics and Statistics. 90(3):518-537. 
Meyer, J-B. 2001. Network approaches versus brain drain lessons from the diaspora, International Migration, 39(5):91-110.

Meyer, J-B., Wattiaux, J-P. 2006. Diaspora Knowledge Networks: Vanishing Doubts and Increasing Evidence. International Journal on Multicultural Societies. 2006, vol.8, no.1, pp. 4-24.

Nagaoka, S., Igami, M., Walsh, J.P. 2013. International collaborations in science, why and how: evidence from scientists' survey in the US and Japan. Working paper. Hitostubashi University.

Roodman, D. 2011. Fitting fully observed recursive mixed-process models with cmp. Stata Journal. 11(2):159-206.

Saxenian, A. 1994. Regional Advantage. Harvard University Press, Cambridge, MA.

Saxenian, A. 2002. The Silicon Valley connection: Transnational networks and regional development in Taiwan, China, and India. Science Technology \& Society. 7: 117-149

Saxenian, A. 2005. From brain drain to brain circulation: Transnational communities and regional upgrading in India and China. Studies in Comparative International Development. 40: 35-61.

Stephan P.E. 1996. The Economics of Science. Journal of Economic Literature , 34(3):11991235.

Stephan P.E. 2010. Economics of Science. In B. H. Hall \& N. Rosenberg, editors, Handbook of Economics and Innovation, Vol. 1, pp. 217-274, Elsevier, 2010

Wagner, C.S., Leydesdorff, L. 2005. Network structure, self-organization, and the growth of international collaboration in science. Research Policy. 34:1608-1618.

Wuchty, S., Jones, B.F., Uzzi, B. The increasing dominance of teams in the production of knowledge. 2007. Science. 316:1036-1039. 


\section{ANNEX A}

\section{Survey response rates}

The following Table A1 reports the number of answers received by country. Answers are further divided into complete answers and partial answers. The latter are answers from respondents who began the survey, but dropped-out before reaching the last question. The total dropout rate is 5 percent. The response rate is 40.6 percent if both complete and partial answers are counted. Reported response rates do not take into account undelivered invitations due to such things as incorrect email address, retirement or death and consequently underestimate the response rate.

Table A1 response rates by country

\begin{tabular}{lcccccc}
\hline & Panels & $\begin{array}{c}\text { Total } \\
\text { Answers }\end{array}$ & $\begin{array}{c}\text { Of which } \\
\text { complete }\end{array}$ & $\begin{array}{c}\text { Of which } \\
\text { dropout }\end{array}$ & $\begin{array}{c}\text { Total } \\
\text { Response } \\
\text { Rate }\end{array}$ & $\begin{array}{c}\text { Complete } \\
\text { Response } \\
\text { Rate }\end{array}$ \\
\hline Australia & 1,571 & 676 & 610 & 66 & $43.00 \%$ & $38.80 \%$ \\
Belgium & 706 & 302 & 244 & 58 & $42.80 \%$ & $34.60 \%$ \\
Brazil & 1,537 & 762 & 692 & 70 & $49.60 \%$ & $45.00 \%$ \\
Canada & 2,455 & 1,020 & 897 & 123 & $41.50 \%$ & $36.50 \%$ \\
Denmark & 513 & 227 & 208 & 19 & $44.20 \%$ & $40.50 \%$ \\
France & 3,839 & 1,618 & 1,367 & 251 & $42.10 \%$ & $35.60 \%$ \\
Germany & 4,380 & 1,326 & 1,147 & 179 & $30.30 \%$ & $26.20 \%$ \\
India & 1,380 & 627 & 484 & 143 & $45.40 \%$ & $35.10 \%$ \\
Italy & 2,779 & 1,917 & 1,759 & 158 & $69.00 \%$ & $63.30 \%$ \\
Japan & 5,250 & 1,860 & 1,678 & 182 & $35.40 \%$ & $32.00 \%$ \\
Netherlands & 1,036 & 391 & 345 & 46 & $37.70 \%$ & $33.30 \%$ \\
Spain & 2,303 & 1,228 & 1,080 & 148 & $53.30 \%$ & $46.90 \%$ \\
Sweden & 882 & 353 & 301 & 52 & $40.00 \%$ & $34.10 \%$ \\
Switzerland & 919 & 356 & 320 & 36 & $38.70 \%$ & $34.80 \%$ \\
UK & 3,695 & 1,355 & 1,183 & 172 & $36.70 \%$ & $32.00 \%$ \\
U.S. & 14,059 & 5,165 & 4,512 & 653 & $36.70 \%$ & $32.10 \%$ \\
Total & 47,304 & 19,183 & 16,827 & 2,356 & $40.60 \%$ & $35.60 \%$ \\
\hline & & & & &
\end{tabular}

Response rates by scientific field are reported in Table A2. Participation was highest for scientists in earth and environmental sciences and lowest for scientists in biology.

Table A2 response rates by field

\begin{tabular}{lcccccc}
\hline & Panels & Total & Of which & Of which & $\begin{array}{c}\text { Total } \\
\text { Response } \\
\text { Rate }\end{array}$ & $\begin{array}{c}\text { Complete } \\
\text { Response } \\
\text { Rate }\end{array}$ \\
\hline Biology & 15,290 & 5,810 & 5,097 & 713 & $38.00 \%$ & $33.30 \%$ \\
Chemistry & 15,549 & 6,324 & 5,524 & 800 & $40.70 \%$ & $35.50 \%$ \\
Earth \& Environment & 8,616 & 3,956 & 3,532 & 424 & $45.90 \%$ & $41.00 \%$ \\
Materials Science & 7,849 & 3,093 & 2,674 & 419 & $39.40 \%$ & $34.10 \%$ \\
Total & 47,304 & 19,183 & 16,827 & 2,356 & $40.60 \%$ & $35.60 \%$ \\
\hline
\end{tabular}


We have assessed nonresponse bias by comparing respondents against nonrespondents. Comparison is done for two characteristics known for the entire panel and sample: total citations received by the underlying article and number of co-authors. Total citations are likely positively correlated with the eminence of the scientist and could potentially reflect differentials in the propensity to answer related to how busy the respondent is. Because the number of co-authors was a basis for a branching question in the survey, more co-authors meant that more questions were asked. Therefore, it is potentially associated with dropping out of the survey. Tests for equality of means are performed for each pair of country samples (Table A3). A relatively higher propensity to answer from authors with better-cited papers is found for France, Italy, Spain and the U.S. Authors of papers with more co-authors are also more likely to have answered from Brazil, Germany, Italy and the U.S. However, the difference in the average number of co-authors also in this cases appears to be quite small.

Table A3 Analysis of nonresponse biases for the number of co-authors

\begin{tabular}{|c|c|c|c|}
\hline & & $\begin{array}{l}\text { Total } \\
\text { Cites }\end{array}$ & $\begin{array}{c}\text { Number of } \\
\text { authors }\end{array}$ \\
\hline \multirow[t]{2}{*}{ Australia } & mean diff. & -0.039 & 0.035 \\
\hline & st.err. & 0.098 & 0.142 \\
\hline \multirow[t]{2}{*}{ Belgium } & mean diff. & -0.268 & -0.274 \\
\hline & st.err. & 0.162 & 0.222 \\
\hline \multirow[t]{2}{*}{ Brazil } & mean diff. & 0.088 & 0.397 \\
\hline & st.err. & 0.046 & $0.125^{*}$ \\
\hline \multirow[t]{2}{*}{ Canada } & mean diff. & 0.009 & 0.16 \\
\hline & st.err. & 0.063 & 0.105 \\
\hline \multirow[t]{2}{*}{ Denmark } & mean diff. & -0.002 & -0.114 \\
\hline & st.err. & 0.224 & 0.242 \\
\hline \multirow[t]{2}{*}{ France } & mean diff. & 0.122 & 0.029 \\
\hline & st.err. & $0.058^{*}$ & 0.094 \\
\hline \multirow[t]{2}{*}{ Germany } & mean diff. & 0.158 & 0.205 \\
\hline & st.err. & 0.092 & $0.099 *$ \\
\hline \multirow[t]{2}{*}{ India } & mean diff. & 0.029 & 0.008 \\
\hline & st.err. & 0.052 & 0.096 \\
\hline \multirow[t]{2}{*}{ Italy } & mean diff. & 0.181 & 0.288 \\
\hline & st.err. & $0.061 *$ & $0.12 *$ \\
\hline \multirow[t]{2}{*}{ Japan } & mean diff. & 0.089 & 0.112 \\
\hline & st.err. & 0.052 & 0.08 \\
\hline \multirow[t]{2}{*}{ Netherlands } & mean diff. & 0.069 & 0.031 \\
\hline & st.err. & 0.124 & 0.178 \\
\hline \multirow[t]{2}{*}{ Spain } & mean diff. & 0.161 & 0.051 \\
\hline & st.err. & $0.064^{*}$ & 0.095 \\
\hline \multirow[t]{2}{*}{ Sweden } & mean diff. & -0.04 & 0.089 \\
\hline & st.err. & 0.133 & 0.188 \\
\hline \multirow[t]{2}{*}{ Switzerland } & mean diff. & 0.212 & 0.206 \\
\hline & st.err. & 0.2 & 0.2 \\
\hline \multirow[t]{2}{*}{ UK } & mean diff. & 0.143 & 0.123 \\
\hline & st.err. & 0.083 & 0.108 \\
\hline U.S. & mean diff. & 0.354 & 0.146 \\
\hline
\end{tabular}




\section{ANNEX B}

The average estimated differentials between nonmigrant researchers, foreign born and returnees in collaboration propensity might be affected by the specific conditions of the destination country, such as the strength of the national research base. In previous model specifications (section 4.1) we have controlled for this effect by introducing destination country dummies. Here we further explore the potential differentials of destination countries by estimating separate models for different pools of countries. In order to have sufficiently large sub-samples, we split the core countries into three groups: US, European countries, other countries. In the three following tables we report the estimated results for selected models. The evidence suggests that the mobility effects on the propensity to have international collaborations persist across the subgroups and that our previous results concerning international collaboration are not fully driven by a specific subset of destination countries.

Table B1- Ordered probit model on international network size, by destination area. Dependent variable NETWORK SIZE.

\begin{tabular}{|c|c|c|c|}
\hline Models & $\begin{array}{c}\text { I } \\
\text { USA }\end{array}$ & $\begin{array}{c}\text { II } \\
\text { EUROPE }\end{array}$ & $\begin{array}{c}\text { III } \\
\text { OTHER }\end{array}$ \\
\hline \multirow[t]{2}{*}{ FOREIGN BORN } & $0.235^{* * *}$ & $0.277 * * *$ & $0.387 * * *$ \\
\hline & $(0.038)$ & $(0.039)$ & $(0.057)$ \\
\hline \multirow[t]{2}{*}{ RETURNED } & $0.1996^{* * *}$ & $0.183^{* * *}$ & $0.312^{* * *}$ \\
\hline & $(0.062)$ & $(0.030)$ & $(0.041)$ \\
\hline \multirow[t]{2}{*}{ AGE } & $0.0139 * * *$ & 0.002 & $0.004 * *$ \\
\hline & $(0.002)$ & $(0.001)$ & $(0.002)$ \\
\hline \multirow[t]{2}{*}{ INDEPENDENT } & $0.134 * *$ & $0.363^{* * *}$ & $0.351 * * *$ \\
\hline & $(0.053)$ & $(0.034)$ & $(0.055)$ \\
\hline \multirow[t]{2}{*}{ FEMALE } & $-0.168^{* * *}$ & $-0.253^{* * *}$ & $-0.170^{* * *}$ \\
\hline & $(0.043)$ & $(0.030)$ & $(0.049)$ \\
\hline \multirow[t]{2}{*}{ COLLAB IMPORTANCE } & $0.153^{* * *}$ & $0.221 * * *$ & $0.162^{* * *}$ \\
\hline & $(0.017)$ & $(0.014)$ & $(0.019)$ \\
\hline Institution dummy & Yes & Yes & Yes \\
\hline Current country dummies & $\mathrm{No}$ & Yes & Yes \\
\hline Field dummies & Yes & Yes & Yes \\
\hline \multirow[t]{2}{*}{ Constant cut 1} & $0.672 * * *$ & $-0.235^{* *}$ & $1.058^{* * *}$ \\
\hline & $(0.147)$ & $(0.108)$ & $(0.146)$ \\
\hline \multirow[t]{2}{*}{ Constant cut 2} & $1.308^{* * *}$ & $0.362^{* * *}$ & $1.743^{* * *}$ \\
\hline & $(0.147)$ & $(0.108)$ & $(0.147)$ \\
\hline \multirow[t]{2}{*}{ Constant cut 3} & $2.633^{* * *}$ & $1.766^{* * *}$ & $3.152^{* * *}$ \\
\hline & $(0.151)$ & $(0.109)$ & $(0.152)$ \\
\hline Observations & 3,938 & 7,298 & 3,873 \\
\hline Pseudo R-sq & 0.0279 & 0.0477 & 0.0724 \\
\hline Log Lik & -4947.1 & -8419 & -4641.6 \\
\hline Chi-Sq & 283.72 & 843.8 & 724.3 \\
\hline
\end{tabular}


Table B2 - Ordered probit model on international network size. Foreign born splitted according to the entry point in the destination country. Models by destination area.

\begin{tabular}{|c|c|c|c|}
\hline Models & $\begin{array}{c}\text { I } \\
\text { USA }\end{array}$ & $\begin{array}{c}\text { II } \\
\text { EUROPE }\end{array}$ & $\begin{array}{c}\text { III } \\
\text { OTHER }\end{array}$ \\
\hline ENTRY MASTER & $\begin{array}{l}0.130^{*} \\
(0.067)\end{array}$ & $\begin{array}{c}0.119 \\
(0.081)\end{array}$ & $\begin{array}{c}0.439 * * * \\
(0.114)\end{array}$ \\
\hline ENTRY PHD & $\begin{array}{c}0.153^{* * *} \\
(0.058)\end{array}$ & $\begin{array}{c}0.199 * * * \\
(0.068)\end{array}$ & $\begin{array}{c}0.138 \\
(0.092)\end{array}$ \\
\hline ENTRY POSTDOC & $\begin{array}{c}0.273^{* * *} \\
(0.052)\end{array}$ & $\begin{array}{c}0.367 * * * \\
(0.052)\end{array}$ & $\begin{array}{c}0.475^{* * *} \\
(0.076)\end{array}$ \\
\hline ENTRY JOB & $\begin{array}{c}0.610^{* * *} \\
(0.104)\end{array}$ & $\begin{array}{c}0.314 * * * \\
(0.089)\end{array}$ & $\begin{array}{c}0.509 * * * \\
(0.107)\end{array}$ \\
\hline RETURNED & $\begin{array}{c}0.203^{* * *} \\
(0.062)\end{array}$ & $\begin{array}{c}0.184^{* * *} \\
(0.030)\end{array}$ & $\begin{array}{c}0.318^{* * *} \\
(0.041)\end{array}$ \\
\hline AGE & $\begin{array}{c}0.013 * * * \\
(0.002)\end{array}$ & $\begin{array}{c}0.002 \\
(0.001)\end{array}$ & $\begin{array}{c}0.004 * * \\
(0.002)\end{array}$ \\
\hline INDEPENDENT & $\begin{array}{c}0.138^{* * *} \\
(0.053)\end{array}$ & $\begin{array}{c}0.361^{* * *} \\
(0.034)\end{array}$ & $\begin{array}{c}0.339 * * * \\
(0.055)\end{array}$ \\
\hline FEMALE & $\begin{array}{c}-0.169 * * * \\
(0.043)\end{array}$ & $\begin{array}{c}-0.252 * * * \\
(0.03)\end{array}$ & $\begin{array}{c}-0.174^{* * *} \\
(0.049)\end{array}$ \\
\hline COLLAB IMPRTANCE & $\begin{array}{c}0.150^{* * *} \\
(0.017)\end{array}$ & $\begin{array}{c}0.222^{* * *} \\
(0.014)\end{array}$ & $\begin{array}{c}0.162^{* * *} \\
(0.019)\end{array}$ \\
\hline Institution dummy & Yes & Yes & Yes \\
\hline Current country dummies & No & Yes & Yes \\
\hline Field dummies & Yes & Yes & Yes \\
\hline Constant cut1 & $\begin{array}{c}0.614^{* * *} \\
(0.147)\end{array}$ & $\begin{array}{c}-0.233^{* *} \\
(0.108)\end{array}$ & $\begin{array}{c}1.025^{* * *} \\
(0.147)\end{array}$ \\
\hline Constant cut 2 & $\begin{array}{c}1.251^{* * *} \\
(0.148)\end{array}$ & $\begin{array}{c}0.365^{* * *} \\
(0.108)\end{array}$ & $\begin{array}{c}1.711 * * * \\
(0.148)\end{array}$ \\
\hline Constant cut 3 & $\begin{array}{c}2.5807 * * * \\
(0.151)\end{array}$ & $\begin{array}{c}1.7701 * * * \\
(0.109)\end{array}$ & $\begin{array}{c}3.1245^{* * *} \\
(0.152)\end{array}$ \\
\hline Observations & 3,938 & 7,298 & 3,873 \\
\hline Pseudo R-sq & 0.0298 & 0.0483 & 0.0736 \\
\hline Log Lik & -4937.4 & -8414.2 & -4635.4 \\
\hline Chi-Sq & 303.2 & 853.4 & 736.6 \\
\hline
\end{tabular}

